\title{
TRIBUTE
}

\section{LUIZ HILDEBRANDO PEREIRA DA SILVA (1928-2014)}

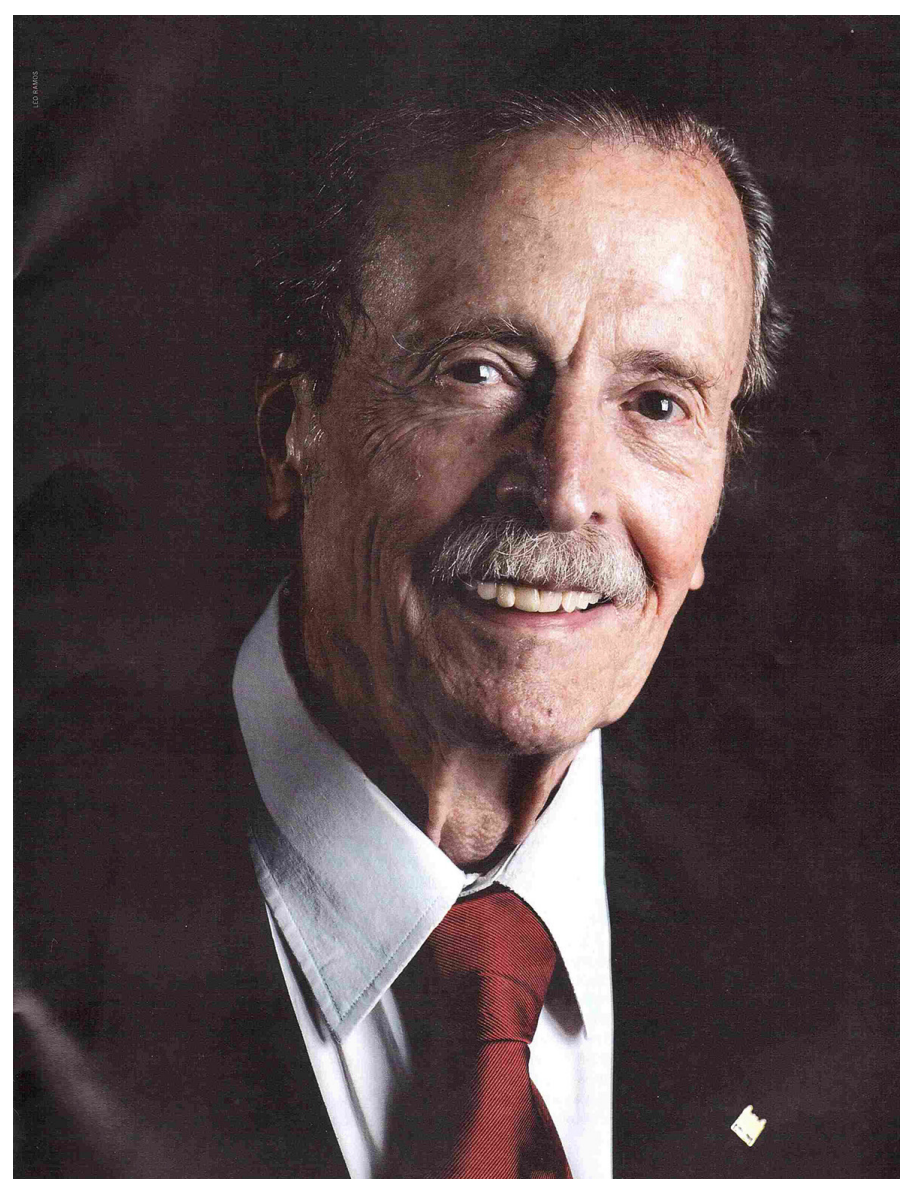

Luiz Hildebrando Pereira da Silva (1928-2014) graduated from the University of São Paulo Medical School in 1953 and shortly thereafter joined the Department of Parasitology, then chaired by Professor Samuel Pessoa, a leading Brazilian parasitologist.

Samuel Pessoa and Luiz Hildebrando both shared a deep commitment to social problems. They considered it their duty to direct their scientific research towards Brazilian people to lessen the burden of parasitic diseases. Therefore, they actively participated as scientists and policy makers in the fight against prevailing parasitic diseases, such as ancylostomiasis, schistosomiasis, Chagas disease and malaria.

Following the military coup of 1964, Luiz Hildebrando and many other scientists were suspended from the University of São Paulo due to undefined "subversive activities". Hildebrando returned to Europe, where he had previously worked for two years in René Thomas' laboratory in Belgium. This time, he went to André Lwoff's laboratory at the Pasteur Institute in Paris, where he met and worked with two other future Nobel Prize winners, François Jacob and Jacques Monot.

After some time, Hildebrando secured his own laboratory at Pasteur Institute and resumed experimental work on malaria, mainly that of African populations, caused by Plasmodium falciparum.

When democracy was restored in Brazil in the 1980's, Hildebrando began the long process of returning home, to collaborate on a project studying malaria in Rondônia with colleagues of the University of São Paulo. Finally, in 1997, after his retirement from the Pasteur Institute, Hildebrando formally returned as a professor to the Department of Parasitology that he had left 30 years ago. This time, he became fully involved with Amazonian malaria and, in 1998, he moved to Porto Velho to live and work amidst the disease.

Hildebrando's permanent fight to solve the practical, day-to-day problems caused by malaria in Rondônia includes over 200 publications, which underpin his scientific contribution to basic and applied research on parasitic diseases. Particularly important was his participation in unveiling the widespread prevalence of asymptomatic malaria in Amazonian native populations and the urgency for its control. Among his latest achievements is the creation of an Institute (IPEPATRO) for the study of tropical pathologies, alongside his permanent involvement with decision making, at both a state and federal level, for improving the control of parasitic diseases.

Erney Plessmann CAMARGO

Professor Emérito da Faculdade de Medicina e do Instituto de Ciências Biomédicas da Universidade de São Paulo erney@usp.br 